\title{
Bosma Syndrome "Mimic" in a Young Infant - Case Report and Literature Review
}

\author{
Rashmi N*, Thotambailu A, Prakash BG, Malini B and Babu AR
}

Departments of Pediatrics, Otorhinolaryngology and Ophthalmology, JSS Medical College, JSSAHER, Mysuru, India

*Corresponding author: Rashmi N, Department of Pediatrics, JSS Medical College, JSSAHER, Mysuru, India, Tel: +91 9986035197, E-mail: dr.rashminagaraj@gmail.com

Citation: Rashmi N, Thotambailu A, Prakash BG, Malini B, Babu AR (2020) Bosma Syndrome "Mimic" in a Young Infant - Case Report and Literature Review. J Paedatr Neonatal Dis 5(1): 102

Received Date: July 13, 2020 Accepted Date: December 02, 2020 Published Date: December 04, 2020

\begin{abstract}
Bosma arrhinia microphthalmia syndrome is a rare entity of unknown etiology, characterized by abnormalities of the nose and eyes and hypogonadotropic hypogonadism.

We report a 7-month-old male baby presenting with right sided choanal atresia and right anophthalmia with normal genitalia. However, arrhinia which is a key feature in Bosma syndrome was not present. So, it is best described here as it's mimic.

This can be explained by the fact that SMCHD1 gene mutations involving the ATPase domain contribute to distinct phenotypic spectra, ranging from craniofacial malformation and reproductive disorders to muscular dystrophy. These are presumed to be consistent with complex oligogenic mechanisms resulting in pleiotropic outcomes [1].
\end{abstract}

Keywords: Anophthalmia; Arrhinia; Choanal Atresia; Hypogonadotrophic Hypogonadism, Microphthalmia

\section{Introduction}

Bosma arhinia microphthalmia syndrome (Bosma syndrome) (OMIM 603457) is a congenital condition characterized by microphthalmia with coloboma, arhinia and endocrine findings with normal intelligence and brain structure. This condition is very rare with unknown prevalence. Fewer than 100 cases of the condition have been described in the medical literature with lesser than 50 case reports and series [2]. It is caused by heterozygous mutation in the SMCHD1 gene (614982) on chromosome 18p11 [3].

The other names for this condition include, arhinia choanal atresia and microphthalmia; arhinia, choanal atresia, microphthalmia and hypogonadotropic hypogonadism; BAM syndrome; BAMS; Bosma syndrome; Gifford-Bosma syndrome; hyposmia-nasal and ocular hypoplasia-hypogonadotropic hypogonadism syndrome; and Ruprecht Majewski syndrome.

\section{Case Report}

\section{History}

A 7-month-old male infant was brought with history of right mucoid nasal discharge and noisy breathing since birth. There was no history of fever, cough, breathing difficulty or any foreign body insertion into the nose. Parents also complained about the fused eyelids on the right side. The child was born to a non-consanguinously married couple, with an uneventful antenatal, natal and postnatal history, developmentally normal and immunised to date, with adequate nutritional intake and coming from a lower socio-economic status. There was no significant past history or any birth defects in other family members or close relatives (three generation pedigree was normal).

\section{Clinical Examination}

Baby was active, playful, with no pallor or icterus and normal systemic examination. There was right nasal discharge and right anophthalmia (Figure 1; written informed consent obtained), with left eye being normal (no cataract or coloboma). However, the external appearance of the nose was normal with depressed right vestibule. Cotton wool test showed absent flickering on the right side as also absent fogging on the cold spatula. Infant feeding tube could not be passed through the right posterior choana. These findings were clinically suggestive of right choanal atresia. Throat and ear examination were normal. No other obvious external congenital anomaly was noted. External genitalia were normal. Examination of the parents did not reveal any congenital abnormality. 

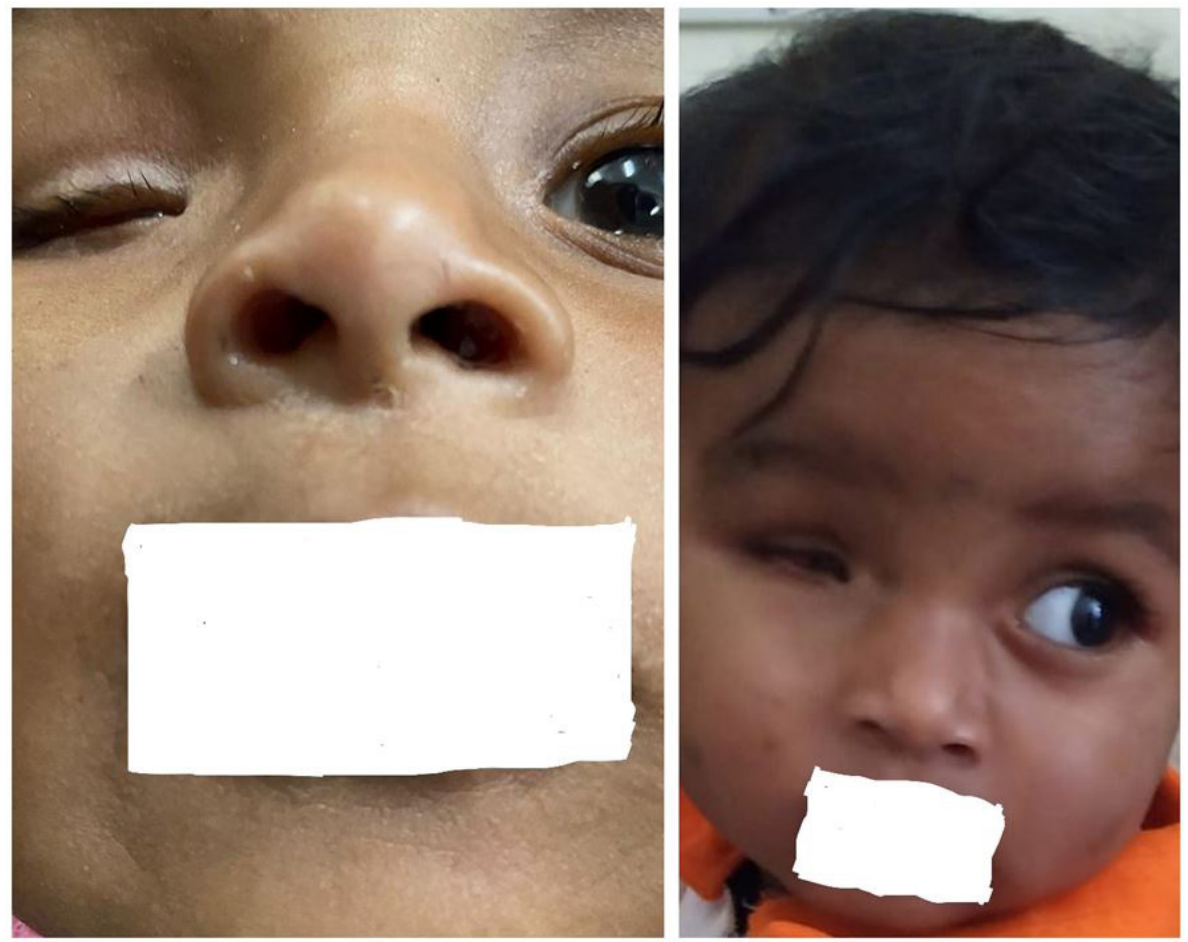

Figure 1: Shows right nasal discharge and right anophthalmia

\section{Investigations}

Showed evidence of iron deficiency anemia with mildly elevated WBC count and normal renal and liver function tests. Brain stem evoked response audiometry showed normal hearing sensitivity in both the ears. 2D Echo and ultrasound examination of the abdomen and pelvis were normal. Plain CT scan of the paranasal sinuses (Figure 2) showed soft tissue attenuation in left mastoid air cells and middle ear cavity, with normal olfactory bulbs and nasolacrimal ducts and hypoplastic right eyeball and optic nerve, probably due to secondary anophthalmia and normal left eyeball. The endocrinology work up including FSH, LH, Testosterone and thyroid profile was normal. Genetic studies could not be done as the parents were not willing for the same due to financial constraint.

\section{collage 2}

2 images, May 2020

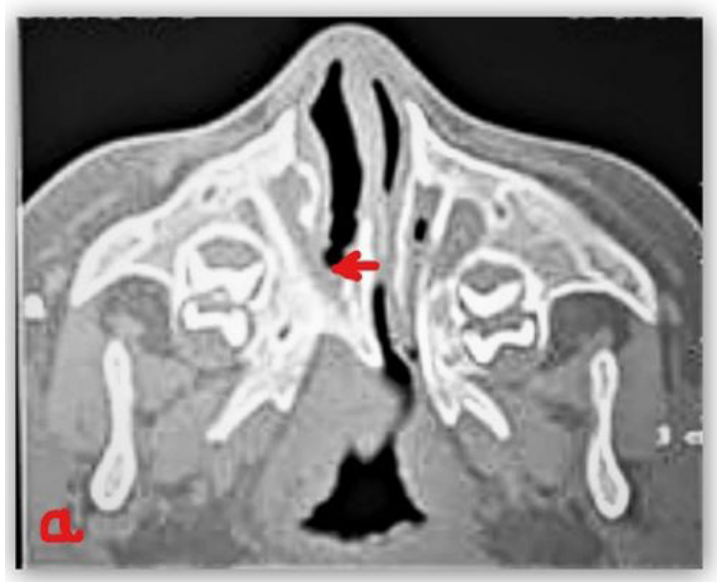

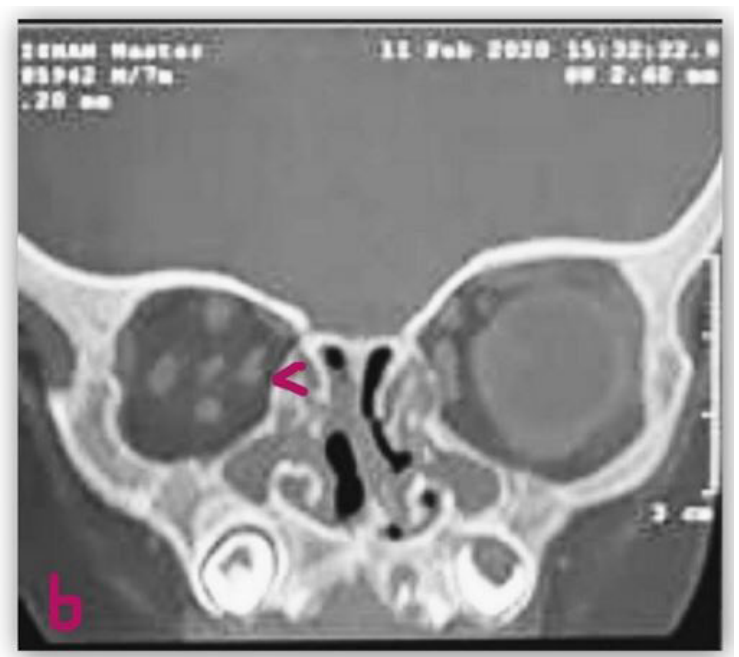

Figure 2: CT of paranasal sinuses a: Membranous and bony part of the right choana on axial section; b. Right eye anophthalmous on coronal section

\section{Differential Diagnosis}

This is represented in the diagnostic flow chart. 


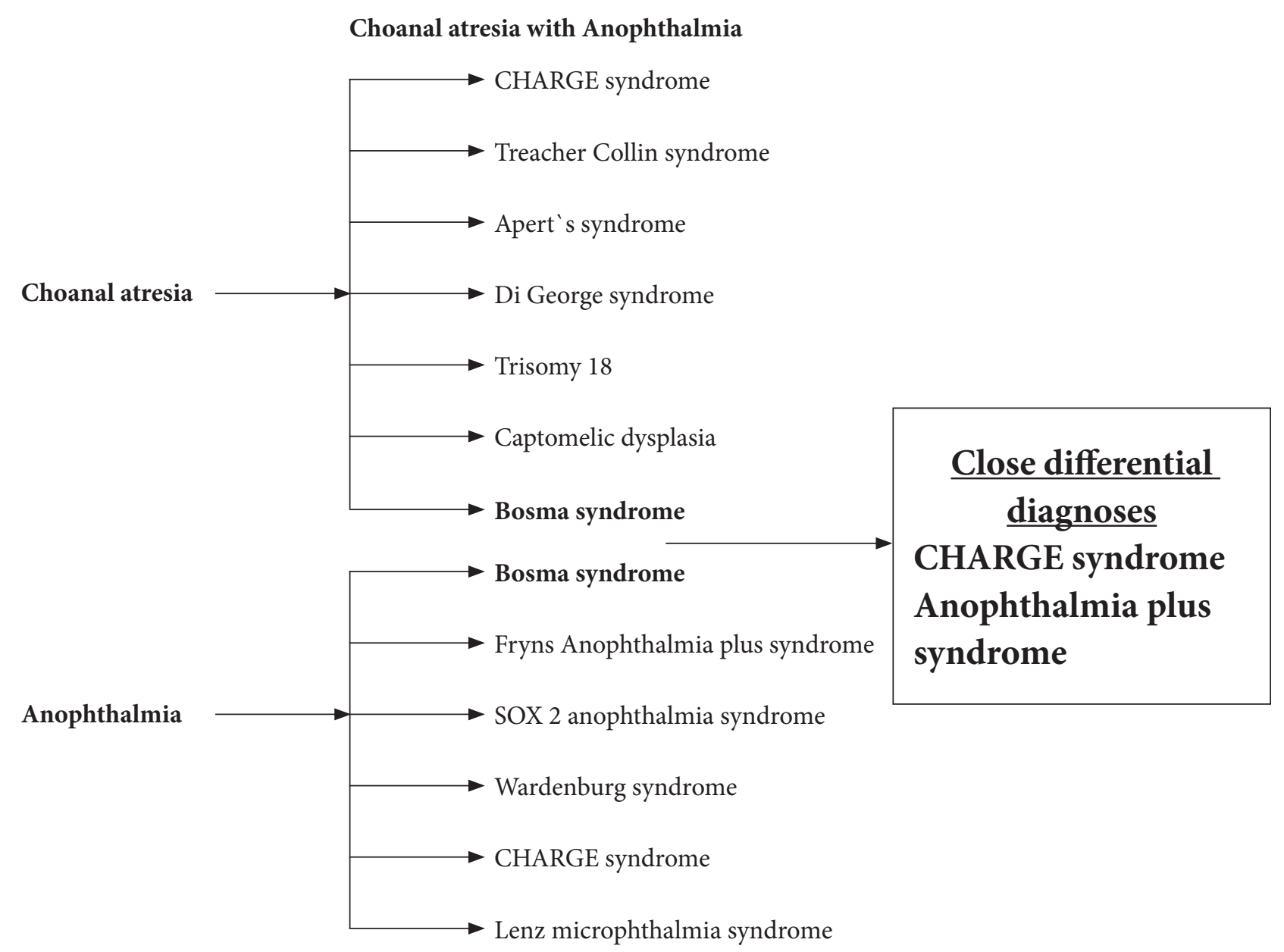

\section{Management}

Choanal atresia with Anophthalmia

The child was taken up for surgery, and the procedure included right sided recanalization of choanal atresia followed by placement of foley`s catheter into the right nostril (Figure 3). This was accompanied by supportive treatment and IV antibiotics. The foley`s catheter was subsequently removed after 1 week and further examination of the meatus revealed intact patency (Figure 3). The child was then discharged and is being followed up, with no fresh complaints.

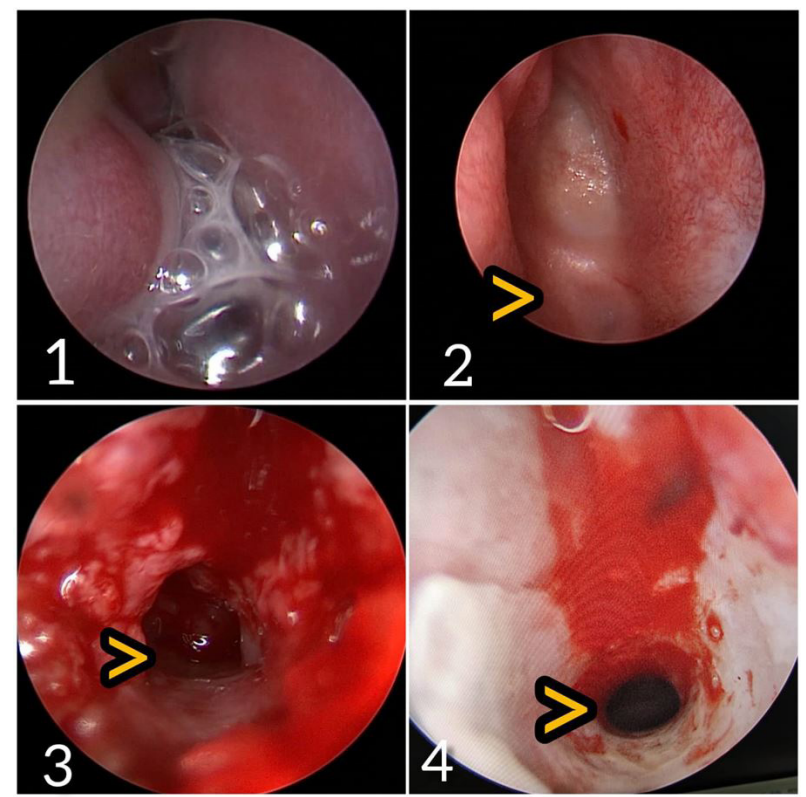

Figure 3: 1. Diagnostic nasal endoscopy showing nasal secretions in the right nasal cavity; 2. Atretic choana; 3. Recanalized choana; 4 . Recanalized choana after 2 weeks 


\section{Discussion}

Bosma arhinia microphthalmia syndrome (BAMS) is a rare condition characterized by nasal and ocular anomalies and problems of the reproductive system.

The important feature of BAMS is arhinia, i.e; the absence of an external nose. However, a few individuals may have a hypoplastic nose and some may have an absent olfactory bulb resulting in loss of smell. The eyeballs are abnormally small (microphthalmia) or absent (anophthalmia), which causes severe vision impairment or blindness. Additional common eye abnormalities include coloboma and cataract [2].

The other head and face anomalies which can occur in these people include high-arched or cleft palate, absence of paranasal sinuses, choanal atresia, nasolacrimal duct stenosis and a hypoplastic maxilla. Many of these abnormalities are responsible for breathing difficulty in the affected children. Abnormal pinna may be found in a few children [2]. The child described here presented to us mainly with right nasal discharge and noisy breathing since birth due to choanal atresia and was also found to have anophthalmia [2].

Another important feature of this syndrome is hypogonadotropic hypogonadism. This can result in delayed puberty, if not recognized and treated early. Affected males may also have underdeveloped reproductive tissues and undescended testes (cryptorchidism) and inguinal hernias [2]. The child reported had normal genitalia, as also his endocrinology works up. However, he needs regular follow up till puberty to detect any problems early thus leading to timely intervention.

\section{Genetics}

BAMS is usually caused by mutations in the SMCHD1 gene with other unknown genes being rarely responsible. The SMCHD1 protein plays a role in silencing certain genes. It is also important for development of the nose, eyes, and other structures of the head and face. Changes in this gene may lead to abnormal silencing of genes involved in the development of head and face, which could explain arhinia, microphthalmia, and other characteristic facial abnormalities of BAMS. Abnormal nasal development may affect gonadotropin releasing hormone $(\mathrm{GnRH})$ neurons, which originate in the developing nose and then migrate to the brain. Resultant abnormal development of these neurons could explain hypogonadotropic hypogonadism in affected individuals [4,5]. This condition is inherited in an autosomal dominant pattern and majority of the cases result from new mutations in the gene and can occur in people with no family history of the disorder. This fact is highlighted in the case presented here.

\section{Conclusion}

It is important to be aware of this syndrome in a child presenting with nose and eye abnormalities to look for features of hypogonadotropic hypogonadism, so that early intervention could be possible. Even though the child presented here had choanal atresia and anophthalmia, key feature of BOSMA syndrome, namely, arrhinia was absent. So, it is best described here as it's mimic.

\section{Literature Review: (Table)}

Gifford et al. (1972) reported two unrelated male patients with congenital absence of the nose and anterior nasopharynx [6]. These patients were restudied by Bosma et al. (1981) and reported that they also had hypoplasia of the eyes, sensory abnormalities of taste and smell, impaired vision with cataracts and colobomata, bilateral inguinal hernias, cryptorchidism, and hypogonadotropic hypogonadism with normal intelligence [7]. In 1978, arhinia, choanal atresia, microphthalmia, and cleft palate were reported by Ruprecht and Majewski in 2 daughters of healthy parents [8].

\begin{tabular}{|c|c|c|c|c|c|c|c|}
\hline & Arrhinia & $\begin{array}{c}\text { Microphthalmia } \\
\text { Anophthalmia }\end{array}$ & $\begin{array}{c}\text { Choanal } \\
\text { atresia }\end{array}$ & $\begin{array}{c}\text { Hypogonadotropic } \\
\text { hypogonadism }\end{array}$ & $\begin{array}{c}\text { Cataracts } \\
\text { Coloboma }\end{array}$ & $\begin{array}{c}\text { Development/ } \\
\text { Intelligence }\end{array}$ & Cryptorchidism \\
\hline Gifford et al. (1972) & Present & - & - & - & - & - & - \\
\hline Ruprecht and Majewski (1978) & Present & Present & Present & - & - & - & - \\
\hline Bosma et al. (1981) & Present & Present & Absent & Present & Present & Normal & Present \\
\hline Thiele et al. (1996) & Present & Present & Present & - & - & Normal & - \\
\hline Olsen et al. (2001) & Present & Present & & - & Present & - & - \\
\hline Becerra-Solano et al. (2016) & Present & Present & Present & - & - & - & Present \\
\hline Brasseur et al. (2016) & Present & Present & - & Present & Present & Normal & - \\
\hline Gordon et al. (2017) & Present & - & Absent & Present & - & - & - \\
\hline Child reported here (2020) & Absent & Present & Present & Absent & Absent & Normal & Absent \\
\hline
\end{tabular}

Note on other findings: The additional findings reported by these authors included sensory abnormalities of taste and smell, bilateral inguinal hernias, cleft palate, hypertelorism, preauricular pits, bilateral absence of twelth ribs, nasolacrimal duct obstruction, micropenis and absent olfactory bulbs, high arched palate 
Thiele et al. (1996) reported a 3-generation German family in which a 5-year-old girl with arrhinia, hypertelorism, left sided microphthalmia and right-sided clinical anophthalmia, high palate, choanal atresia, preauricular pits, and bilateral absence of the twelfth ribs with normal motor and mental development. They considered the condition to be inherited in a dominant fashion with reduced penetrance [9].

A review of 22 previously reported cases of congenital absence of the nose, with frequent association of ocular anomalies, including hypertelorism, unilateral or bilateral microphthalmia, iris coloboma, and occluded or absent nasolacrimal ducts was conducted by Olsen et al. in 2001. They also noted associated central nervous system anomalies like frontal encephalocele and absent olfactory tracts [10].

Becerra-Solano et al in 2016 reported the fifteenth case of BAMS, and the first reported Mexican case in a 19-month-old Mexican boy with arhinia, bilateral clinical anophthalmia, choanal atresia, and high palate, along with micropenis, undescended testes, and hypoplastic scrotum [11].

Brasseur et al. in 2016 suggested the criteria for BAMS should include arhinia, midface hypoplasia and normal cognition, as well as hypogonadotropic hypogonadism in males, with microphthalmia with or without coloboma, high-arched palate, anosmia, absent paranasal sinuses, and absent olfactory bulbs being additional important findings. They made this suggestion after studying the clinical findings in 14 reported BAMS patients [2].

Gordon et al. (2017) observed pubertal delay in all 3 female patients and suggested that reproductive axis defects associated with arhinia are likely secondary to a defect in $\mathrm{GnRH}$ neuron production in, or migration from, the olfactory placode [4].

In 2017, Shaw et al. [1] summarized the clinical findings in 40 patients from 38 families with arrhinia, including patients previously reported by others $[3,6,7-11]$.

\section{References}

1. Shaw ND, Brand H, Kupchinsky ZA, Bengani H, Plummer L, et al. (2017) SMCHD1 mutations associated with a rare muscular dystrophy can also cause isolated arhinia and Bosma arhinia microphthalmia syndrome. Nat Genet 49: 238-48.

2. Brasseur B, Martin CM, Cayci Z, Burmeister L, Lisa AS (2016) Bosma arhinia microphthalmia syndrome: Clinical report and review of the literature. Am J Med Genet 170: 1302-7.

3. Graham JM, Lee J (2006) Bosma arhinia microphthalmia syndrome. Am J Med Genet Part A 140: 189-93.

4. Gordon CT, Xue S, Yigit G, Filali H, Chen K, et al. (2017) De novo mutations in SMCHD1 cause Bosma arhinia microphthalmia syndrome and abrogate nasal development. Nat Genet 49: 249-55.

5. Jansz N, Chen K, Murphy JM, Blewitt ME (2017) The Epigenetic Regulator SMCHD1 in Development and Disease. Trends Genet 33: 233-43.

6. Gifford GH, Swanson L, MacCollum DW (1972) Congenital absence of the nose and anterior nasopharynx: report of two cases. Plast Reconst Surg 50: 5-12.

7. Bosma JF, Henkin RI, Christiansen RL, Herdt JR (1981) Hypoplasia of the nose and eyes, hyposmia, hypogeusia, and hypogonadotropic hypogonadism in two males. J Craniofac Genet Dev Biol 1: 153-84.

8. Ruprecht KW, Majewski F (1978) Familiary arhinia combined with peters' anomaly and maxilliar deformities, a new malformation syndrome. Klin Monatsbl Augenheilkd 172: 708-15.

9. Thiele H, Musil A, Nagel F, Majewski F (1996) Familial arhinia, choanal atresia, and microphthalmia. Am J Med Genet 63: 310-13.

10. Olsen OE, Gjelland K, Reigstad H, Rosendahl K (2001) Congenital absence of the nose: a case report and literature review. Pediat Radiol 31: 225-32.

11. Becerra-Solano LE, Chacon L, Morales-Mata D, Zenteno JC, Ramirez-Duenas ML, et al. (2016) Bosma arrhinia microphthalmia syndrome in a Mexican patient with a molecular analysis of PAX6. Clin. Dysmorph 25: 12-5. 